$12-3-2015$

\title{
Racial Attitude (Dis)Similarity and Liking in Same- Race Minority Interactions
}

\author{
Randi L. Garcia \\ Hilary B. Bergsieker \\ University of Waterloo \\ J. Nicole Shelton \\ Princeton University
}

Princeton University, rgarcia@smith.edu

Follow this and additional works at: https://scholarworks.smith.edu/psy_facpubs

Part of the Psychiatry and Psychology Commons

\section{Recommended Citation}

Garcia, Randi L.; Bergsieker, Hilary B.; and Shelton, J. Nicole, "Racial Attitude (Dis)Similarity and Liking in Same-Race Minority Interactions" (2015). Psychology: Faculty Publications, Smith College, Northampton, MA.

https://scholarworks.smith.edu/psy_facpubs/15 
Racial Attitude (Dis)Similarity and Liking in Same-Race Minority Interactions

\author{
Randi L. Garcia \\ Princeton University \\ Hilary B. Bergsieker \\ University of Waterloo \\ J. Nicole Shelton \\ Princeton University
}

Author Note

Randi L. Garcia, Department of Psychology, Princeton University; Hilary B. Bergsieker, Department of Psychology, University of Waterloo; J. Nicole Shelton, Department of Psychology, Princeton University. The first and second author contributed equally to this work.

The pilot study measures come from a larger dataset reported in the second author's dissertation (Bergsieker, 2012; Study 1) and Bergsieker, Shelton, and Richeson (2010; Study 2). This research was presented at a meeting of the Society for Personality and Social Psychology (Austin, Texas, February 2014). The data presented in this manuscript do not overlap with any previous published work. This research was supported in part by a National Science Foundation Graduate Research Fellowship awarded to Hilary B. Bergsieker.

We thank Vanessa Boren, Justine Calcagno, Lydia Emery, Mickheila Jasmin, Thomas Kontchou, and Megan Nelson for assistance with behavioral coding in Study 2. We also thank Mark Zanna and Tessa West for comments on a previous version of this manuscript. Address correspondence to Randi L. Garcia, now at: Psychology Department, Clark University, 950 Main Street, Worcester, MA 01610. E-mail: RaGarcia@clarku.edu. 


\begin{abstract}
Two studies investigate the relationship between racial attitude (dis)similarity and interpersonal liking for racial minorities and Whites in same-race and cross-race pairs. In nationally representative and local samples, minorities report personally caring about racial issues more than Whites do (Pilot Study), which we theorize makes racial attitude divergence with ingroup members especially disruptive. Both established friendships (Study 1) and face-to-face interactions among strangers (Study 2) provided evidence for the dissimilarity-repulsion hypothesis in same-race interactions for minorities but not Whites. For minorities, disagreeing with a minority partner or friend about racial attitudes decreased their positivity toward that person. Because minorities typically report caring about race more than Whites, same-race friendships involving shared racial attitudes may be particularly critical sources of social support for them, particularly in predominately White contexts. Understanding challenges that arise in same-race interactions, not just cross-race interactions, can help create environments in which same-race minority friendships flourish.
\end{abstract}




\section{Racial Attitude (Dis)Similarity and Liking in Same-Race Minority Interactions}

Views about race can profoundly shape interactions with both racial outgroup and ingroup members (West, 1993). Psychological research on race relations, however, has primarily examined ways in which negative or discordant racial attitudes undermine White/minority interactions (e.g., Dovidio, Kawakami, \& Gaertner, 2002), but not same-race interactions among Whites or racial minorities. The tacit assumption appears to be that racial attitudes cause friction between but not within groups. In contrast, real-world events suggest that deep disagreements within minority groups indeed arise and can lead individuals to denounce ingroup members whose racial attitudes deviate from their own. For example, Black political and intellectual leaders have derogated the Supreme Court Justice Clarence Thomas as an "Uncle Tom" for his allegedly more pro-White views (Blake, 2014) and the civil rights activist Al Sharpton as a "racial arsonist" for his allegedly anti-White views (Taylor, 2002, p. 120). Clearly, ingroup status need not imply racial attitude agreement.

As social psychology expands to incorporate a diverse range of perspectives, examining experiences of minorities in same-race interactions represents a critical advance. Our research investigates intra-minority dynamics, focusing on initial encounters and established relationships between minorities of the same race. We test the novel prediction that disagreement about racial attitudes is especially disruptive to interpersonal liking in same-race minority interactions. Attitude dissimilarity even in arbitrary domains can impair same- and cross-race interactions, and racial attitude dissimilarity among disadvantaged minorities may incur particularly negative interpersonal consequences, undermining collective identity and perpetuating power disparities.

Prior research suggests that people expect ingroup members to have similar racial attitudes to their own (Rokeach \& Rothman, 1965), that dissimilarity in attitudes fosters disliking 
(Byrne, 1961), that attitude similarity or dissimilarity matters more for personally relevant issues (Marks \& Miller, 1987), and that racial issues and attitudes are especially important to minorities (Davis et al., 2007). Therefore, we predict that disagreement will negatively affect minorities' same-race interactions more than Whites' same-race interactions. Furthermore, racial attitude dissimilarity should have more negative implications for minorities'same-race interactions—in which attitude similarity is expected - than cross-race interactions. In contrast, we predict that Whites — who typically report caring less about race—will comparably dislike Whites and minorities with dissimilar racial attitudes. To ground our argument theoretically we offer a brief overview of work on assumed similarity and dissimilarity-repulsion effects, we then describe research on similarity in same- and cross-race interactions. Last, we discuss effects of the attitude type (e.g., racial attitudes) and group on similarity-attraction processes.

\section{Assumed Similarity and Dissimilarity-Repulsion Effects}

People often expect others to agree with them, as evidenced by extensive work on assumed similarity (Human \& Biesanz, 2011; Kenny, 1994), social projection (Krueger, 2007) and false consensus (Marks \& Miller, 1987). Individuals overestimate attitude similarity not only for strangers but also friends (Baldassarri \& Bearman, 2007; Robbins \& Krueger, 2005), and assume that ingroup others share their attitudes and values more than those from outgroups (Alabastro, Rast, Lac, Hogg, \& Crano, 2013; Byrne \& Wong, 1962; Chen \& Kenrick, 2002; Robbins \& Krueger, 2005), even in minimal groups (Allen \& Wilder, 1979; Diehl, 1988).

Attitude similarity facilitates interpersonal attraction in initial contact and maintenance of long-term friendships (Byrne, 1961; Selfhout, Denissen, Branje, \& Meeus, 2009). Although similarity increases attraction (e.g., Byrne, 1971), later work suggests that dissimilarity more powerfully decreases attraction (e.g., Rosenbaum, 1986), producing greater shifts from default 
evaluations. When people expect attitude similarity, confirming a partner's actual attitude similarity is unlikely to increase already high liking levels (Norton, Frost, \& Ariely, 2007). However, when people expect attitude similarity (e.g., for ingroup members) but encounter attitude dissimilarity, that discrepancy compels greater revisions to liking (Chen \& Kenrick, 2002), triggering a cascade of negative impressions due to perceived dissimilarity (Norton et al., 2007). When people expect attitude dissimilarity (e.g., for outgroup members), learning that a partner's attitudes are instead similar should increase liking more than confirming the partner's attitudes are indeed dissimilar would decrease liking. Greater weight of unexpected dissimilarity implies greater disliking for same- than cross-race partners with dissimilar racial attitudes.

\section{Attitude (Dis)Similarity in Same- and Cross-Race Contexts}

Intergroup research on similarity has found that assuming outgroup members' attitudes differ from one's own can undermine cross-race interactions (Rokeach, Smith, \& Evans, 1960), whereas learning that an outgroup member has attitudes matching one's own can increase liking and decrease aggression (Donnerstein \& Donnerstein, 1975; Insko, Nacoste, \& Moe, 1983), reduce intergroup threat (Garcia-Retamero, Müller, \& Rousseau, 2012), and improve expectations for cross-race interactions (Mallett, Wilson, \& Gilbert, 2008; West, Magee, Gordon, $\&$ Gullett, 2014). For example, Whites varying in anti-Black prejudice respond favorably to a Black person perceived to share similar attitudes (Byrne \& McGraw, 1964). When choosing interaction partners, Whites and Blacks prefer a cross-race partner whose attitudes match theirs to a same-race partner with dissimilar attitudes (Rokeach \& Mezei, 1966). Few other studies test effects of dissimilarity on interpersonal liking in same-race interactions or for minorities.

Theorizing about reactions to dissimilarity in same-race interactions draws upon the black sheep effect (BSE; Marques, Yzerbyt, \& Leyens, 1988), which occurs when people 
derogate deviant ingroup members (or elevate normative ingroup members) to a more extreme degree than outgroup members. For example, people more intensely punish and ostracize ingroup (vs. outgroup) members whose attitudes or behaviors violate general norms (Abrams, Marques, Bown, \& Henson, 2000; Abrams, Palmer, Rutland, Cameron, \& Van de Vyver, 2014). Most BSE studies use norm-violating (not disagreeing) targets, but one set of studies found that attitude dissimilarity leads to greater disliking for an ingroup than outgroup member, whereas attitude similarity did not consistently induce greater liking for ingroup (vs. outgroup) members (Chen \& Kenrick, 2002). Evidently, attitude congruence matters as much or more in intragroup (vs. intergroup) contexts, and ingroup dissimilarities repel more than ingroup similarities attract. We investigate whether these dynamics shift for attitudes directly relevant to group membership and whether repulsion asymmetries arise if the attitude matters more to one group than the other.

\section{Domain of Dissimilar Attitudes}

We hypothesize that people especially dislike ingroup members who disagree with them on attitudes directly related to their group identity. Most prior research on attitude similarity has assessed attitudes unrelated to group identity (e.g., non-partisan attitudes for Democrats vs. Republicans; Chen \& Kenrick, 2002), intentionally superficial (e.g., taste in flooring; Mallett et al., 2008), or linked to superordinate groups (e.g., college students for White vs. minority students; West, Pearson, Dovidio, Shelton, \& Trail, 2009). In a study manipulating gender attitude agreement between opposite-sex small groups, participants - especially womenpreferred opposite-sex outgroups with similar rather than dissimilar gender attitudes (Grant, 1993), but this study's omission of same-sex targets precludes tests of same-sex repulsion for men versus women. In a study addressing domain of dissimilarity, participants in minimal groups supposedly based on preference for Klee versus Kandinsky paintings inferred that 
outgroup members differed from them more on aesthetic than general attitudes (Allen \& Wilder, 1979). Similarity-attraction and dissimilarity-repulsion processes may be particularly potent when the attitude closely corresponds to the basis of group membership.

Personal or vested interest in the attitude (dis)similarity domain amplifies attraction and repulsion (Marks \& Miller, 1987). Targets with dissimilar attitudes on topics people personally find interesting (vs. uninteresting) elicit more dislike (Clore \& Baldridge, 1968). People assume greater attitude similarity when they believe a policy will personally affect them (Crano, 1983) or they hold a numeric minority viewpoint (Mullen, 1983; Wetzel \& Walton, 1985), potentially triggering disappointment when they learn others' actual attitudes. Because racial attitudes tend to matter more to minorities, we predict a repulsion asymmetry, with dissimilar racial attitudes leading to greater disliking among same-race minorities than same-race Whites.

Racial attitudes are more personally important for minorities than for Whites, based on representative survey data. Blacks were 4-8 times more likely than Whites to report race relations as one of the most important issues to them in 1983 (Davis et al., 2007), to list racial problems as the most important challenge facing the country in 1992 (Miller \& the National Election Studies, 1994), and to cite racism and race relations as the single most important problem facing the next generation in 2000 (Sack \& Elder, 2000). Occupying a lower-status societal position may make improved race relations a long-term security goal for minorities to meet their occupational, income, and even physical safety needs (Eibach \& Ehrlinger, 2006). Given greater personal relevance of racial attitudes to minorities, assumed attitude similarity among ingroup members, and heavy weighting of dissimilarity, we predict the strongest dissimilarity-repulsion effects for minorities who disagree on racial attitudes with a racial ingroup member. 


\section{Overview of Studies}

Two studies investigate the interpersonal consequences of having racial attitudes that differ from a partner's attitudes in the context of ongoing friendships (Study 1) and face-to-face interactions with strangers (Study 2). Our research questions focus on agreement versus disagreement in people's attitudes toward racial outgroups (not ingroups). For both same- and cross-race pairs we examine outgroup racial attitudes - henceforth simply racial attitudes namely, the extent to which participants hold favorable or unfavorable attitudes toward other racial groups either in general (Study 1) or toward a specific relevant outgroup (Study 2).

\section{Pilot Study: Racial Attitude Importance}

Representative national survey data indicate that, on average, Blacks report personally caring more about race than Whites do (Davis et al., 2007). We used the same survey items to test whether this finding replicates at the university where we conducted Studies 1 and 2.

\section{Participants and Procedures}

Of 558 undergraduates initially recruited, 357 self-identified as White, 64 as Asian/Asian American, 75 as African American/Black, 56 as Latino, 2 as Native American, 3 as Pacific Islander, and 1 Middle Eastern. ${ }^{1}$ The sample $\left(M_{\mathrm{age}}=19.6\right)$ included 200 men and 358 women.

\section{Measures}

General Social Survey (Davis et al., 2007) items assessed the personal importance and salience of race relations on 1-to-4 scales. Personal importance $(\alpha=.76)$ items were "How important is the issue of race relations to you?" (not important at all - one of the most important) and "How concerned are you personally about race relations?" (not concerned at all

\footnotetext{
${ }^{1}$ Although the participants (from a larger dyadic study on relationships) are nested in dyads, the ICC for the 2-item composite was small and non-significant, $I C C=.093, p=.209$, so participants were analyzed as independent here.
} 
— very concerned). The salience item was "How often would you say that you and your friends in general think about race relations?" (almost never — very often).

\section{Results and Discussion}

As hypothesized, minorities reported personally caring more about race relations $(M=$ $2.70, S D=0.77)$ than did Whites $(M=2.41, S D=0.67), t(369.2)=4.44, p<.01, d=0.40($ see Figure 1). A set of orthogonal contrasts indicated that race relations were significantly more important to Blacks than to Asians and Latinos (combined), contrast $=0.58, p<.01$, but that Latinos and Asians did not differ, contrast $=0.08, p=.52$; due to low power, no tests were performed for subgroups with $n<5$. Minorities also reported that race was more salient to them $(M=2.24, S D=0.86)$ than did Whites $(M=1.87, S D=0.68), t(344.4)=5.33, p<.01, d=0.48 .^{2}$ The results from this university sample are consistent with our claim that attitudes about race relations are typically more personally meaningful and salient for minorities than Whites. ${ }^{3}$

\section{Study 1: Racial Attitude (Dis)Similarity Between Friends}

Study 1 tests whether racial attitude (dis)similarity is related to the quality of established cross- and same-race friendships. Same- and cross-race pairs of friends completed measures of racial attitudes and friendship quality. Consistent with prior BSE studies, we expected a slight preference for same- over cross-race friends when dyad members' racial attitudes agree. More importantly, we predicted that participants would perceive same-race (vs. cross-race) friends who disagree with their racial attitudes more negatively. Because race matters more to minorities than Whites, according to the Pilot Study and representative polling data, this samerace dissimilarity-repulsion effect should be stronger for minorities than Whites. Thus, we

\footnotetext{
${ }^{2}$ Due to significant heterogeneity of variance, $t$-tests do not assume equal variances.

${ }^{3}$ The remaining GSS-Race items $(\alpha=.53)$ "How firm are you about your opinion on race relations?" and "How much information do you have about the issue of race relations?" also revealed firmer attitudes on race relations among minorities $(M=2.73, S D=0.63)$ than Whites $(M=2.61, S D=0.59), t(387.8)=2.10, p=.04, d=0.20$.
} 
predict that for friends with dissimilar racial attitudes, minorities in same-race friendships will report lower friendship quality than Whites in same-race friendships or minorities in cross-race friendships.

\section{Method}

Participants. Initially 363 undergraduates completed a questionnaire about a specific same- or cross-race friend of the same gender attending the same university. Next, participants were asked to invite their specified friend to complete the questionnaire for $\$ 5$. In Wave 1 , participants and friends filled out and mailed back paper questionnaires, yielding a friend response rate of 24\%. In Waves 2 and 3, participants completed the questionnaire online and could email it to friends, plus the researchers sent reminders to eligible friends ${ }^{4}$, raising the friend response rate to $51 \%$. The overall friend response rate $(41.9 \%)$ did not differ for sameversus cross-race friendships, $\chi^{2}(1, N=363)=1.46, p=.24$. Data collection occurred in 3 waves across 3 years with a target of over 100 dyads, and we did not test our hypotheses until all data collection was completed. The target demographic included Whites, Blacks, Latinos, and Asians (the largest racial groups on campus), oversampling Blacks and Latinos.

Because only complete dyads — with attitude data from both dyad members — could be used to test our hypothesis, analyses excluded 212 solo respondents (whose friends did not participate), leaving 151 dyads. Of the 151 original participants (i.e., the first person recruited in each dyad), we excluded 12 people not from the target population (1 who attended another school, 1 minor, 10 from discrepant racial groups_-self-identified as Pacific Islander or “other”). Analyses excluded 24 additional friends who were ineligible because they were a different

\footnotetext{
${ }^{4}$ Over $15 \%$ of incomplete dyads included an ineligible friend.
} 
gender $(n=9)$, a minor $(n=3)$, from another school $(n=1)$, a "duplicate" friend selected by a prior participant $(n=1)$, or from an "other" racial background $(n=10) .{ }^{5}$ Finally, analyses excluded 10 participants for dyad-composition issues: 2 dyads in which one person misperceived their friend's race and 8 dyads with minorities in the "different-race" condition who selected outgroup minority friends (e.g., Blacks with Latino friends). (This cross-minority dyad subgroup was too small for meaningful analysis; moreover, predictions for these dyads are unclear because their share racial minority status but are not specific racial ingroup members.) The final 105 dyads contained 64 same-race friendships (34 White/White, 17 Asian/Asian, 12 Black/Black, 1 Latino/Latino) and 41 cross-race friendships (20 White/Asian, 5 White/Black, 16 White/Latino). Participants (68.5\% female, $\left.M_{\text {age }}=19.6\right)$ self-identified as White $(n=109)$, Black (29), Latino (18), and Asian (54).

Design and procedure. We used a 2 (participant race: minority vs. White) $\times 2$ (dyad composition: same- vs. cross-race) between-subjects design. A random-number generator assigned participants to select a friend of the same gender and approximate age who attended the same college and whose race/ethnicity was either the "same as you" or "different from you." The sample included 11 participants who selected an eligible friend whose race did not match their assigned same- or cross-race condition, but who were retained for analyses in their selfimposed condition because this error did not interact with any findings of interest (all $p s>.25$ ).

Measures. Participants completed several measures related to their friendship and their racial attitudes. The measures relevant to the present research question are described below.

Background information. Participants indicated their gender, race/ethnicity, age, and

\footnotetext{
${ }^{5}$ In most instances in which participants picked "other" for their friend's race/ethnicity, they specified that their friend was multiracial. In 3 instances, participants named specific subgroups (Ghanian, Ethiopian, West Indian) that could conceivably be categorized within the broader category "Black/African American." Including these 3 dyads does not change the reported results: The predicted four-way interaction remains significant, $p=.03$.
} 
class year, and this information for their friend. In addition, they indicated their relationship duration ("less than a week," "a few weeks," "about a month," "a few months," "6 months but less than a year," and "2 years or longer") and "How well does this person know you?" from 1 (not at all) to 7 (very well). ${ }^{6}$

Racial attitudes. Participants evaluated two items $(\alpha=.61)$ indexing affective attitudes toward outgroups: "I feel negatively towards people of racial/ethnic group other than my own" and "I feel positively towards people of racial/ethnic group other than my own" (reverse-coded), from 1 (strongly disagree) to 7 (strongly agree). ${ }^{7}$ Using an identical measure of outgroup racial attitudes for Whites and minorities ensures that if dyad type (same- vs. cross-race) moderates dissimilarity-repulsion effects, this effect cannot reflect differences in measures across groups.

Friendship quality. The McGill Friendship Questionnaire (Mendelson \& Aboud, 1999) assessed friendship quality. We combined 25 items (see Appendix A; e.g., "I like a lot") from the Respondent's Affection and Friend's Functions subscales to create a friendship quality composite $(\alpha=.97)$. Responses ranged from 1 (strongly disagree) to 7 (strongly agree).

\section{Results}

Analyses of racial attitudes and friendship quality confirmed that dyad members who were initially recruited to participate by the experimenter versus nominated by a friend did not differ on the effect of actor's attitudes on friendship quality, the effect of partner's attitudes, the effect of disagreement, the intercepts of quality, or the error variances, $\Delta \chi^{2}(5)=2.25, p=.81$. Analyses collapse across this variable, using the terms participant and friend interchangeably. Dyadic mixed-model analyses - the indistinguishable Actor-Partner Interdependence

\footnotetext{
${ }^{6}$ The questionnaire also included several measures (e.g., attachment style, self-monitoring, public selfconsciousness, perspective taking, self-presentation strategies) unrelated to the current research project.

${ }^{7}$ The same pattern of results reported below was found when analyzing these racial attitudes items separately.
} 
Model (APIM, Kenny, Kashy, \& Cook, 2006)—controlled for non-independence. Participant race is a mixed variable (varying within and across dyads), so dyad members are treated as indistinguishable in all dyadic analyses: Variances of dyad members are constrained to be equal. Adjusting for non-independence using the Satterthwaite approximation can yield fractional degrees of freedom (Kenny et al., 2006). Model predictors included participant race $(-1=$ minority, 1 = White $)$, dyad type $(-1=$ cross-race, 1 = same-race $)$, actor racial attitudes, and partner racial attitudes, plus all interaction terms. Racial attitudes were grand-mean centered.

Background information. The high intraclass correlation for length of relationship, ICC $=.78, \mathrm{p}<.01$, indicates that dyad members provided convergent estimates and that dyads ranged in their friendship length. Length ranged from "a few months or less" (17.2\%) or "6 months to less than a year" (19.0\%) to "a year or longer" (63.8\%) but did not differ for same- versus crossrace friends, $t(102)=0.57, p=.57$, nor did ratings of "How well do you know this person?" $(M=$ $5.37, S D=1.34)$ reveal differences, $t(102)=0.76, p=.45$. Participants assigned to nominate a same-race (vs. cross-race) friend did not select friends whom they had known longer or better. ${ }^{8}$

Racial attitudes. Dyad members showed above-chance similarity in racial attitudes, ICC $=.24, p<.01$. No significant differences in racial attitudes emerged for Whites $(M=2.00, S D=$ 1.04) versus minorities $(M=1.94, S D=1.06), b=0.03, t(205.73)=0.37, p=.72, d=0.06$; participants with a White $(M=2.00, S D=1.01)$ versus minority $(M=1.95, S D=1.09)$ friend, $b$ $=0.02, t(205.73)=0.32, p=.75, d=0.05$; or for same- $(M=1.95, S D=0.96)$ versus cross-race $(M=2.01, S D=1.17)$ friendships, $b=-0.03, t(102)=-0.36, \mathrm{p}=.72, \mathrm{~d}=-0.06$.

Friendship quality. Participant race, dyad type, participant racial attitudes, and friend racial attitudes were tested as predictors of friendship quality. Significant main effects emerged

\footnotetext{
${ }^{8}$ Friend completion rates were unrelated to how long or well participants reported knowing them. Original participants whose friends did (vs. did not) participate did not differ on these measures, $F_{\mathrm{s}}(1,361)<1$.
} 
for participant race and participant racial attitudes: Whites (marginal $M=5.87, S E=0.09$ ) reported higher friendship quality than minorities (marginal $M=5.44, S E=0.09$ ), $b=0.22$, $t(186.71)=3.70, p<.01$, and the more negatively participants felt about outgroups the lower their friendship quality, $b=-0.29, t(181.73)=-5.00, p<.01$. A significant 2-way interaction of participant and friend racial attitudes, $b=0.18, t(95)=2.59, p=.01$, indicated that greater attitude similarity was associated with higher friendship quality.

As predicted, dyad type significantly moderated the interaction of participant and friend racial attitudes, $b=0.20, t(95)=2.85, p<.01$. Racial attitude similarity was associated with higher friendship quality in same- than cross-race friendships, $b=0.27, t(95)=2.78, p<.01$, whereas racial attitude dissimilarity was associated with lower friendship quality in same- than cross-race friendships, $b=-0.17, t(95)=-1.51, p=.14$, though not statistically significant. Critically, as predicted, the strength of these effects differed for White and minority participants, as indicated by a significant 4-way interaction of participant race, dyad type, participant racial attitudes, and friend racial attitudes, $b=-0.19, t(132.29)=-3.00, p<.01$. The effect of dyad type on friendship quality did not differ based on the type of attitude similarity (i.e., sharing positive vs. negative attitudes) or attitude dissimilarity (i.e., participant positive/friend negative vs. participant negative/friend positive) for either race, so analyses collapsed across types of similarity and across types of dissimilarity. ${ }^{9}$ When dyad members' racial attitudes agree (see Figure 2), friendship quality was higher in same- than cross-race friendships, $b=0.27, t(95)=$ $2.78 p<.01$, regardless of participant race, $b=-0.12, t(147.74)=-1.39, p=.17$. However, when dyad members have dissimilar (i.e., disagreeing) racial attitudes the effects of dyad type differ by participant race, $b=0.30, t(164.30)=3.08, p<.01$. For same-race friendships with dissimilar

\footnotetext{
${ }^{9}$ The effect of dyad type did not differ for Whites by dissimilarity type $\Delta b=-0.21, p=.44$, or similarity type, $\Delta b=-$ $0.05, p=.82$, or for minorities by dissimilarity type $\Delta b=-0.34, p=.23$, or similarity type, $\Delta b=0.23, p=.38$.
} 
racial attitudes, minorities report lower friendship quality than the other three conditions [White same-race: $b=0.59, t(95)=3.62, p<.01 ;$ minority cross-race: $b=-0.47, t(119.81)=-3.05, p<$ .01 ; \& White cross-race: $b=0.46, t(119.86)=2.98, p<.01]$. Our model explained $23.80 \%$ of the variance in friendship quality. As predicted, when friends' racial attitudes agree, pro-ingroup bias emerges, but when attitudes disagree, same-race minority friends report the lowest friendship quality of all groups.

\section{Discussion}

In Study 1 we found evidence for a dissimilarity-repulsion effect among minorities in same-race friendships. Specifically, in friendships minorities reported lower relationship quality with same- than cross-race friends where there was racial attitude dissimilarity. In contrast, when friends shared similar racial attitudes, they tended to report better relationship quality in same- than cross-race friendships, consistent with prior BSE studies. Together with the pilot study data indicating that racial issues tend to matter more to minorities than Whites in this university setting, these results suggest that the relative importance of the attitude topic may affect the magnitude of dissimilarity-repulsion effects.

In Study 1 we assumed friends had experienced ample opportunity over time to discuss racial attitudes and gauge agreement, but Study 2 tests whether the same dissimilarity-repulsion asymmetry for minorities versus Whites emerges in face-to-face interactions among strangers. In short-term interaction settings, racial attitudes may be less salient or masked by other attitudes. Indeed, Whites often avoid discussing race in cross-race interactions between strangers (Johnson, Olson, \& Fazio, 2009), limiting learning about each others' racial attitudes. Study 2 therefore investigates whether the hypothesized disagreement pattern emerges primarily when people discuss race, potentially providing more direct access to each other's racial attitudes. 


\section{Study 2: Racial Attitude (Dis)Similarity and Discussing Race in Face-to-Face Encounters}

Study 2 connects racial attitude (dis)similarity to interpersonal liking among strangers in same- and cross-race interactions in the laboratory. Testing these processes between strangers is critical because disagreement on racial attitudes may undermine same-race minority friendships from the outset. Study 2 used the previously validated Attitudes Towards Blacks and Attitudes Towards Whites racial attitudes scales (ATB \& ATW; Brigham, 1993), so accordingly we recruited only White and Black participants (the two groups most divergent in importance ascribed to racial attitudes in the Pilot Study). Black and White strangers completed an online measure of racial attitudes (in a separate session) and interacted briefly with a minority or White partner. We coded the extent to which dyads talked about race to investigate whether talking about race enhances the minority-White asymmetry in the dissimilarity-repulsion process.

\section{Method}

Participants. We recruited White and Black undergraduates and randomly assigned them to same-gender pairs with same- or cross-race partners. Of 172 dyads completing the study, 19 were excluded from analyses: 6 due to prior acquaintance, 2 due to suspicion, and 11 due to self- or partner-perceived identification with an ineligible racial group (2 Asian, 8 Latino, 1 unknown). Dyadic analyses necessarily excluded 26 dyads in which one or both participants failed to complete the appropriate attitude measure, as described below. The final 127 dyads (65.4\% female, $\left.M_{\text {age }}=19.9\right)$ included 44 White/White dyads, 56 White/Black dyads, and 27 Black/Black dyads. Sample size was based on participant availability across two academic years of recruiting to obtain over 100 dyads (at least 30 per type), and we did not test our hypotheses until data collection was completed.

Procedure. To downplay our interest in racial attitude (dis)similarity and interaction 
quality, without mentioning race we recruited participants to two ostensibly distinct studies: an online "Attitudes and Associations" study for $\$ 8$ or credit and a lab-based "Task Performance" study for $\$ 12$ or credit. People who completed either "study" were invited to complete the other on a different day (median session separation $=7$ days). Of all those who completed the lab session, $85 \%$ completed the online measures afterward, $10 \%$ beforehand, and $5 \%$ never. Dyadic analyses of (dis)similarity require attitude data for both dyad members, thus excluding 26 dyads in which one or both participants skipped the online measures (14 dyads) or reported their racial background as "Other" and were thus not routed to the appropriate racial attitudes measure (12 dyads). No significant racial attitude differences emerged for participants retained versus dropped due to missing partner data, $t(276)<1$.

Online session. Participants completed an online survey, described as an examination of "personal attitudes, social attitudes, and associations," on a different date from the lab session.

Lab session. A White female experimenter blind to participants' racial attitudes seated participants together at a table. After consenting to participate and be videotaped, participants completed three interpersonally challenging tasks. First, they spent 4 minutes discussing a topic adapted from Dovidio et al. (2002):

"Dating in the current era has some advantages and disadvantages to dating in earlier periods. Please consider and discuss what you personally feel are these advantages and disadvantages. What are your experiences with dating in a racially, religiously, and economically diverse society?"

Next, participants decided "which items would be most valuable for an incoming student to bring to college" (Dovidio, 2001). Participants ranked 10 items (e.g., computer, alarm clock, family photos) individually and then were instructed to "please decide together which items would be 
most valuable," emphasizing that "it is important that you both agree about your joint rankings." Participants received as much time as needed to finalize joint rankings. The final task involved playing Connect Four (a game like tic-tac-toe), competing to get four Xs or Os in a row first. Participants played for 4 minutes, completing up to three games.

After the interaction, participants completed questionnaires about the interaction and their partner in separate rooms. Participants reported their demographics, estimated the interaction duration, recalled the Connect Four game(s) outcome, reported their partner's demographics, and indicated any prior acquaintance. Last, participants were debriefed, thanked, and compensated.

Measures. Participants completed a measure of explicit outgroup attitudes in the online session and measures about their interaction with another participant in the lab session. ${ }^{10}$

Racial attitudes. White participants reported their attitudes toward Blacks (ATB $\alpha=.70$ ) and Black participants indicated their attitudes towards Whites (ATW $\alpha=.68$; Brigham, 1993). These widely used, well-validated scales were developed in tandem to enable precise assessment of outgroup racial attitudes held by Whites and Blacks, respectively. To equate the scales, our analyses used only 8 parallel items from the two scales (see Appendix B). Responses range from 1 (strongly disagree) to 7 (strongly agree).

Interaction satisfaction. After the interaction, 4 items assessed satisfaction $(\alpha=.83$; dyadic $I C C=.26, p<.01)$ : "I enjoyed working with the other participant," "I was satisfied with our interaction," "I like the other participant," and "The other participant was comfortable to work with," on scales from 1 (strongly disagree) to 7 (strongly agree).

Partner positivity. Participants reported how positively they viewed their partner with 5

\footnotetext{
${ }^{10}$ The online session also included several measures (e.g., "opener" scale, emotion regulation, race IAT, selfconsciousness, self-monitoring) for separate research projects on impression management and affective responses to aversive racism, as did the lab session (e.g., emotion suppression, affect, state self-control, self-presentation goals).
} 
items $(\alpha=.68$; dyadic ICC $=.15, p=.08)$ about whether the partner "was an efficient problem solver," "seemed very intelligent," "appeared to be very considerate," "seemed trustworthy," and "appeared to be nervous" (reverse-coded) from 1 (strongly disagree) to 7 (strongly agree). ${ }^{11}$

Behavioral coding. Three coders blind to condition listened to the audio recordings and independently coded the extent to which each participant discussed race during the interaction, using a 7-point scale (inter-rater $\alpha=.80$ ). Because discussion of race by either dyad member can reveal (dis)similar racial attitudes, a dyad-level indicator of discussing race was created by computing the maximum of the two dyad members' scores on that coded behavior.

\section{Results}

We again used the indistinguishable APIM, to account for non-independence in dyadic interactions. Model predictors included participant race $(-1=$ minority, $1=$ White $)$, dyad type $(-$ $1=$ cross-race, $1=$ same-race), actor racial attitudes, and partner racial attitudes, plus all interaction terms. Racial attitudes were grand-mean centered.

Interaction satisfaction. Whites (marginal $M=5.77, S E=0.08$ ) reported more satisfaction than Blacks (marginal $M=5.51, S E=0.10), b=0.13, t(228.25)=2.16, p=.03$, and participants reported more satisfaction in cross-race (marginal $M=5.84, S E=0.09$ ) than samerace (marginal $M=5.44, S E=0.09)$ dyads, $b=-0.20, t(117)=-3.03, p<.01$. The interaction of actor and partner racial attitudes predicting interaction satisfaction was moderated by actor race, $b=-0.20, t(236.64)=-2.11, p=.04$, and by dyad type, $b=0.22, t(117)=2.07, p=.04$.

Notably, these lower-order effects were qualified by the hypothesized 4-way interaction of actor race, dyad type, actor racial attitudes, and partner racial attitudes, $b=-0.20, t(236.64)=-$

\footnotetext{
${ }^{11}$ Meta-perceptions (e.g., "I believe the other participant liked me") were also measured using a 3-item scale. Similar results to interaction satisfaction and partner positivity emerged for meta-perceptions, but meta-perceptions do not bear directly on our predictions about how attitude disagreement undermines people's own liking for others.
} 
2.21, $p=.03$. This interaction indicates that implications of racial attitude (dis)similarity for satisfaction differ for same- versus cross-race dyads and for Blacks versus White participants. ${ }^{12}$ When dyad members' racial attitudes agreed (see Figure 3), participant race was unrelated to their satisfaction [actor race: $b=0.01, t(238.00)=0.11, p=.92$; dyad type: $b=-0.07, t(117)=-$ $0.81, p=.42$; actor race by dyad type: $b=-0.03, t(238.00)=-0.36, p=.72]$. However, when dyad members' racial attitudes disagreed, there was a significant interaction of actor race and dyad type, $b=0.23, t(117)=-3.27, p<.01$, such that Black participants with Black (same-race) partners felt less satisfied with the interaction than White participants with White (same-race) partners, $b=0.48, t(117)=3.28, p<.01$, and less satisfied than Black participants with White (cross-race) partners, $b=-0.56, t(153.17)=-3.58, p<.01$. In contrast, White participants' satisfaction with the interaction was unrelated to the race of their partner, $b=-0.11, t(188.62)=-$ $0.92, p=.36$. Our model explained $5.5 \%$ of the variance in interaction satisfaction.

Partner positivity. Participants perceived their partners marginally more positively in cross-race (marginal $M=5.44, S E=0.08$ ) than same-race (marginal $M=5.23, S E=0.08$ ) dyads, $b=-0.11, t(117)=-1.78, p=.08$. As expected, dyad type moderated the interaction of actor and partner racial attitudes, $b=0.25, t(117)=2.63, p=.01$. Moreover, as predicted, there was a significant 4-way interaction between actor race, dyad type, actor racial attitudes, and partner racial attitudes, $b=-0.23, t(237.72)=-2.60, p=.01 .^{13}$ When dyad members' racial attitudes agreed (see Figure 4), race was unrelated to positive partner perceptions [actor race: $b=-0.02$, $t(234.50)=-0.30, p=.77$; partner race: $b=-0.10, t(234.50)=-1.47, p=.14$; dyad race: $b=$

\footnotetext{
12 The dyad type effect on satisfaction did not differ for Blacks by dissimilarity type, $\Delta b=0.19, p=.55$, or similarity type, $\Delta b=0.37, p=.15$, or Whites by dissimilarity type, $\Delta b=0 . .37, p=.15$, or similarity type, $\Delta b=0.19, p=.36$. Subsequent analyses collapse across the two types to examine simply similarity versus dissimilarity.

${ }^{13}$ The dyad type effect on positivity did not differ for Blacks by dissimilarity type, $\Delta b=0.07, p=.81$, or similarity type, $\Delta b=0.34, p=.14$, or Whites by dissimilarity type, $\Delta b=-0.20, p=.35$, or similarity type, $\Delta b=0.28, p=.16$. Subsequent analyses collapse across the two types to examine simply similarity versus dissimilarity.
} 
$0.04, t(117)=0.57, p=.57]$. However, when dyad members had dissimilar racial attitudes, actor race and dyad type significantly interacted, $b=0.18, t(233.44)=2.07, p=.04$, such that Black participants with Black (same-race) partners felt less satisfied with the interaction than White participants with White (same-race) partners, $b=0.32, t(117)=2.43, p=.02$, and than Black participants with White (cross-race) partners, $b=0.44, t(160.52)=3.07, p<.01$. In contrast, White participants did not think less positively of White (same-race) partners than Black (crossrace) partners, $b=-0.08, t(201.09)=-0.75, p=.46$. Our model explained $2.4 \%$ of the variance in partner positivity.

Talking about race. Analyses revealed some discussion of race $(M=2.87$ on a 1-7 scale), which differed for White/White $(M=2.43, S D=0.94)$, White/Black $(M=2.99, S D=$ $1.25)$, and Black/Black $(M=3.33, S D=1.31)$ dyads, $F(2,124)=5.56, p<.01, \eta_{\mathrm{p}}{ }^{2}=.08$.

To investigate whether the hypothesized disagreement pattern emerges primarily when people discuss race — and thus have more direct access to each other's racial attitudes — we tested the 5-way interaction of actor race, partner race, actor racial attitudes, partner racial attitudes, and the extent to which the dyad talked about race for each outcome variable. (All lower-order interactions were retained.) As expected, the disagreement pattern tended to be stronger when dyads discussed race more: This 5-way interaction was significant for interaction positivity, $b=$ $0.30, t(107)=2.12, p=.04$, and marginally significant for partner positivity, $b=0.21, t(107)=$ $1.68, p=.097$. Tests of higher-order interaction effects involving measured predictors tend to be lower powered (McClelland \& Judd, 1993), so although the latter interaction was marginal, together they suggest that dissimilarity-repulsion processes for minorities in same-race dyads may be intensified when strangers discuss race and can readily infer each other's racial attitudes.

Indeed, for dyads who discussed race more $(+1 S D)$, actor race, partner race, actor racial 
attitudes and partner racial attitudes significantly interacted to predict interaction satisfaction, $b=$ $0.56, t(107)=2.52, p=.01$, and partner positivity, $b=0.57, t(107)=2.87, p<.01$. In contrast, for dyads who discussed race less (-1 SD), this 4-way interaction was not significant for interaction satisfaction, $b=-0.17, t(107)=-0.80, p=.43$, or partner positivity, $b=0.05, t(107)=$ $0.29, p=.77$. For dyads who talked about race more, partner race significantly moderated dissimilarity-repulsion effects on interaction satisfaction for Blacks, $b=-0.89, t(136.38)=-3.49$, $p<.01$, but not Whites, $b=0.23, t(121.68)=0.65, p=.52$, and on partner positivity for Blacks, $b=-0.79, t(143.60)=-3.41, p<.01$, but not Whites, $b=0.35, t(125.41)=1.11, p=.27$.

\section{Discussion}

Study 2 provided support for the dissimilarity-repulsion hypotheses for minorities but not for Whites during a face-to-face interaction with a stranger in the lab. Specifically, when dyad members' racial attitudes disagreed, Blacks in same-race (vs. cross-race) dyads liked partners less and felt less satisfied with the interaction, a pattern not evident for Whites. Analyses of coded behavior provided initial evidence that such asymmetric ingroup-dissimilarity-repulsion effects are stronger for dyads who discussed race more, suggesting that such effects are more likely when interaction partners exchange information about racial attitudes. Thus, repulsion effects may arise from discovering dissimilar attitudes, an emergent property of dyadic interactions, more so than from individual differences associated with racial attitudes.

\section{General Discussion}

Two studies using varied relational settings and attitude measures provide evidence for the dissimilarity-repulsion effects in same-race interactions for minorities when the object of agreement is racial attitudes. Representative polling data and our pilot study from the university where Studies 1 and 2 were conducted reveal that relative to Whites, minorities report greater 
personal importance and salience of race relations. Studies 1 and 2 revealed especially low levels of friendship quality, interaction satisfaction, and partner positivity for minorities whose samerace friends' or interaction partners' racial attitudes disagreed with participants' attitudes. Finally, Study 2 implies such effects may depend on opportunities to discover others' racial attitudes: Disagreement led to disliking only when same-race minority dyads discussed race.

This research extends the literature on similarity and attraction by investigating varied types of interpersonal encounters. Across face-to-face first encounters and extended friendships, we found negative effects of attitude dissimilarity for same-race minority pairs. Investigating face-to-face interactions without confederates advances work on similarity-attraction processes (see Sunnafrank \& Miller, 1981), particularly in intra- and intergroup contexts. Our work also makes a novel contribution by, to our knowledge, presenting the first studies to test attitude (dis)similarity effects on dyadic intergroup processes when the attitude in question relates directly to group membership. When navigating unfolding interactions and anticipating future encounters, people may especially value attitude similarity in domains that are more chronically relevant and crucial for collective identity.

\section{Limitations and Future Directions}

One challenge inherent in testing specific outgroup attitude differences in an intergroup context is some inevitable variation in the attitude object depending on one's own racial ingroup. In same-race dyads the outgroup attitudes of both people likely pertain to the same group (e.g., attitudes about Whites in Black/Black interactions), but in cross-race dyads outgroup attitudes likely pertain to each other's groups (e.g., Whites' attitudes about Blacks; Blacks' attitudes about Whites). In same- and cross-race interactions, people may also consider "third-party" outgroups (e.g., White/Black or White/White dyad members may report attitudes about Asians or Latinos). 
The two studies address this potential ambiguity from different angles. Study 1, which draws on a more diverse participant sample, preserves generality and consistency in measurement by asking all participants about their positive or negative attitudes toward other racial groups in general (not a specific group). This approach draws on empirical work showing that prejudice levels directed at distinct outgroups tend to correlate highly (e.g., Zick et al., 2008) and shift in tandem (e.g., contact with one outgroup often improves attitudes toward numerous outgroups; Lolliot et al., 2013). By contrast, Study 2, which includes only White and Black participants, clearly specifies the relevant outgroup (Whites or Blacks) using established measures designed for this purpose (Brigham, 1993). This more focused approach still retains attitude object consistency insofar as almost half the items are constant for all participants, such as "Racial integration (of schools, businesses, residences, etc.) has benefited both Whites and Blacks" (see Appendix B). Indeed, we neither theorize nor operationalize racial attitudes as showing a zero-sum relationship in attitudes toward racial ingroups versus outgroups. People can express warmth toward outgroups (as in Study 1) or embrace diversity and contact with outgroups (as in Study 2) without disliking ingroup members. Moreover, members of the same or different racial groups can readily agree_ or disagree_- with each other about whether racial integration benefits society. Finally, ambiguity within dyads about the outgroup attitude object is less relevant for the most theoretically important comparison, the dissimilarity-repulsion asymmetry between same-race minority dyads and same-race White dyads.

Although Study 1 included several different racial minority groups, we lacked sufficient power to test for differences in this repulsion asymmetry across racial minority dyad members or among their White partners in cross-race dyads. Insofar as some minority groups (e.g., Blacks) may assign relatively more importance to racial attitudes than others do, they may experience 
stronger repulsion effects. Future research is needed to investigate variation across minorities.

These studies do not directly manipulate awareness of an interaction partner's racial attitudes during an interpersonal encounter. To examine interpersonal interactions and friendship as they naturally unfold, we opted not to expose participants explicitly to each others' racial attitudes, so we cannot know exactly how participants become aware (consciously or not) of their partner's attitudes. Notably, in Study 2 this pattern was stronger when dyads discussed race. Future work may investigate how people verbally and nonverbally convey racial attitudes in cross- and same-race interactions. Our findings suggest that, for minorities in a mostly White context, communicating congruent racial attitudes to ingroup others may enhance interactions or relationships, whereas concealment may be more adaptive given incongruent attitudes.

Lastly, one question that remains is the extent to which discovering that our attitudes differ from those of fellow ingroup members can carry intrapersonal costs, depending on the personal significance of that attitude. Individuals may ignore disagreement if an attitude domain does not seem especially important, a process that may be at play when Whites (who in general tend to care less about race) hear another White person make an anti-Black racist comment but neither confront this ingroup member nor experience negative affect, and are indeed more likely to select the racist White person than a Black person as an interaction partner (Kawakami, Dunn, Karmali, \& Dovidio, 2009). Conversely, when an attitude is personally important or definitional for the group, intragroup disagreements may jeopardize one's sense of ingroup belonging, and feelings of deviance may threaten the self (Abrams, Hogg, \& Marques, 2005; Frings, Hurst, Cleveland, Blascovich, \& Abrams, 2012; Hogg \& Smith, 2007). Belongingness concerns may be greater for minorities, who tend to identify more strongly with their race/ethnicity (Crocker, Luhtanen, Blaine, \& Broadnax, 1994), particularly if the disagreement pertains to group 
membership. Disagreement in racial attitudes among same-race individuals may undermine collective identity (Tajfel \& Turner, 1986), particularly for disadvantaged racial groups.

\section{Conclusion}

The present work contributes to a small but growing body of work on relations within and between minority groups (see e.g., Craig \& Richeson, 2012; Shapiro \& Neuberg, 2008), expanding our understanding of how same-race interactions may succeed or fail based on similar or dissimilar attitudes towards outgroups. If racial attitude dissimilarity for same-race minority interaction partners especially undercuts interaction quality and ingroup friendship development, these dynamics could adversely affect the well-being of minority individuals and communities. Believing that key targets share our attitudes is theorized to serve needs for social support and self-esteem maintenance, particularly when attitude issues are personally involving or when one holds a minority position (Marks \& Miller, 1987). Same-race minority friendships may thus be particularly critical for race-based social support, and better understanding these interaction dynamics can inform efforts to create environments that foster these relationships. 


\section{References}

Abrams, D., Hogg, M. A., \& Marques, J. M. (2005). A social psychological framework for understanding social inclusion and exclusion. In D. Abrams, M. A. Hogg, \& J. M. Marques (Eds.), The social psychology of inclusion and exclusion (pp. 1-24). New York, NY: Psychology Press.

Abrams, D., Marques, J. M., Bown, N., \& Henson, M. (2000). Pro-norm and anti-norm deviance within and between groups. Journal of Personality and Social Psychology, 78, 906-912. doi:10.1037/0022-3514.78.5.906

Abrams, D., Palmer, S. B., Rutland, A., Cameron, L., \& Van de Vyver. J. (2014). Evaluations of and reasoning about normative and deviant ingroup and outgroup members: Development of the black sheep effect. Developmental Psychology, 50, 258-270. doi:http://dx.doi.org/10.1037/a0032461

Alabastro, A., Rast, D., Lac, A., Hogg, M. A., \& Crano, W. D. (2013). Intergroup bias and perceived similarity: Effects of successes and failures on support for in- and outgroup political leaders. Group Processes \& Intergroup Relations, 16, 58-67. doi:10.1177/1368430212437212

Allen, V. L., \& Wilder, D. A. (1979). Group categorization and attribution of belief similarity. Small Group Behavior, 10, 73-80.

Baldassarri, D., \& Bearman, P. (2007). Dynamics of political polarization. American Sociological Review, 72, 784-811. doi:10.1177/000312240707200507

Bergsieker, H. B. (2012). Building, betraying, and buffering trust in interracial and same-race friendships (Doctoral dissertation). Retrieved from ProQuest.

Bergsieker, H. B., Shelton, J. N., \& Richeson, J. A. (2010). To be liked versus respected: 
Divergent goals in interracial interactions. Journal of Personality and Social Psychology, 99, 248-264.

Blake, A. (2014, April 30). Black congressman stands by comment that Clarence Thomas is an “Uncle Tom”. The Washington Post. Retrieved from http://www.washingtonpost.com

Brigham, J. C. (1993). College students' racial attitudes. Journal of Applied Social Psychology, 23, 1933-1967. doi:10.1111/j.1559-1816.1993.tb01074.x

Byrne, D. (1961). Interpersonal attraction and attitude similarity. The Journal of Abnormal and Social Psychology, 62, 713-715. doi:10.1037/h0044721

Byrne, D. (1971). The attraction paradigm. New York: Academic Press.

Byrne, D., \& McGraw, C. (1964). Interpersonal attraction toward Negroes. Human Relations, 17, 201-213. doi:10.1177/001872676401700301.

Byrne, D., \& Wong, T. J. (1962). Racial prejudice, interpersonal attraction, and assumed dissimilarity of attitudes. The Journal of Abnormal and Social Psychology, 65, 246-253. doi:10.1037/h0047299

Chen, F., \& Kenrick, D. T. (2002). Repulsion or attraction? Group membership and assumed attitude similarity. Journal of Personality and Social Psychology, 83, 111-125. doi:10.1037/0022-3514.83.1.111

Clore, G. L., \& Baldridge, B. (1968). Interpersonal attraction: The role of agreement and topic interest. Journal of Personality and Social Psychology, 9, 340-346. doi: $10.1037 / \mathrm{h} 0026085$

Craig, M., \& Richeson, J. (2012). Coalition or derogation? How perceived discrimination influences intraminority intergroup relations. Journal of Personality and Social Psychology, 102, 759-777. 
Crano, W. D. (1983). Assumed consensus of attitudes: The effect of vested interest. Personality and Social Psychology Bulletin, 9, 597-608.

Crocker, J., Luhtanen, R., Blaine, B., \& Broadnax, S. (1994). Collective self-esteem and psychological well-being among White, Black, and Asian college students. Personality and Social Psychology Bulletin, 20, 503-513. doi:10.1177/0146167294205007

Davis, J. A., Smith, T. W., \& Marsden, P. V. (2007). General Social Surveys, 1972-2006 [Computer file]. Chicago: National Opinion Research Center, producer. Storrs, CT: Roper Center for Public Opinion Research, distributor. Available at http://sda.berkeley.edu/D3/GSS06/Doc/gs06.htm

Diehl, M. (1988). Social identity and minimal groups: The effects of interpersonal and intergroup attitudinal similarity on intergroup discrimination. British Journal of Social Psychology, 27, 289-300. doi:10.1111/j.2044-8309.1988.tb00833.x

Donnerstein, E., \& Donnerstein, M. (1975). The effect of attitudinal similarity on interracial aggression. Journal of Personality, 43, 485-502. doi:10.1111/j.14676494.1975.tb00717.x

Dovidio, J. F. (2001). On the nature of contemporary prejudice: The third wave. Journal of Social Issues, 57, 829-849.

Dovidio, J. F., Kawakami, K., \& Gaertner, S. L. (2002). Implicit and explicit prejudice and interracial interaction. Journal of Personality and Social Psychology, 82, 62-68. doi:10.1037/0022-3514.82.1.62

Eibach, R. P., \& Ehrlinger, J. (2006). "Keep your eyes on the prize": Reference points and racial differences in assessing progress toward equality. Personality and Social Psychology Bulletin, 32, 66-77. 
Frings, D., Hurst, J., Cleveland, C., Blascovich, J., \& Abrams, D. (2012). Challenge, threat, and subjective group dynamics: Reactions to normative and deviant group members. Group Dynamics: Theory, Research, and Practice, 16, 105-121. doi:10.1037/a0027504

Grant, P. R. (1993). Reactions to intergroup similarity: Examination of the similaritydifferentiation and the similarity-attraction hypotheses. Canadian Journal of Behavioural Science, 25, 28-44. doi:10.1037/h0078789

Hogg, M. A., \& Smith, J. R. (2007). Attitudes in social context: A social identity perspective. European Review of Social Psychology, 1889-131. doi:10.1080/10463280701592070

Human, L. J., \& Biesanz, J. C. (2011). Through the looking glass clearly: Accuracy and assumed similarity in well-adjusted individuals' first impressions. Journal of Personality and Social Psychology, 100, 349-364. doi:10.1037/a0021850

Insko, C. A., Nacoste, R. W., \& Moe, J. L. (1983). Belief congruence and racial discrimination: Review of the evidence and critical evaluation. European Journal of Social Psychology, 13, 153-174. doi:10.1002/ejsp.2420130206

Garcia-Retamero, R., Müller, S. M., \& Rousseau, D. L. (2012). The impact of value similarity and power on the perception of threat. Political Psychology, 33, 179-193.

Johnson, C. S., Olson, M. A., \& Fazio, R. H. (2009). Getting acquainted in interracial interactions: Avoiding intimacy but approaching race. Personality and Social Psychology Bulletin, 35, 557-571. doi:10.1177/0146167208331160

Kawakami, K., Dunn, E., Karmali, F., \& Dovidio, J. F. (2009). Misreading affective and behavioral responses to racism. Science, 323, 276-278. doi:10.1126/science.1164951

Kenny, D. A. (1994). Interpersonal perception: A social relations analysis. New York, NY: Guilford. 
Kenny, D. A., Kashy, D. A., \& Cook, W. L. (2006). Dyadic data analysis. New York, NY: Guilford.

Krueger, J. I. (2007). From social projection to social behaviour. European Review of Social Psychology, 181-35. doi:10.1080/10463280701284645

Lolliot, S.D., Schmid, K., Hewstone, M., Al Ramiah, A., Tausch, N., \& Swart, H. (2013). Generalized effects of intergroup contact: The secondary transfer effect. In G. Hodson, \& M. Hewstone (Eds.), Advances in intergroup contact (pp. 81-112). London, UK: Psychology Press.

Mallett, R. K., Wilson, T. D., \& Gilbert, D. T. (2008). Expect the unexpected: Failure to anticipate similarities leads to an intergroup forecasting error. Journal of Personality and Social Psychology, 94, 265-277. doi:10.1037/0022-3514.94.2.94.2.265

Marks, G., \& Miller, N. (1987). Ten years of research on the false-consensus effect: An empirical and theoretical review. Psychological Bulletin, 102, 72-90. doi:10.1037/00332909.102.1.72

Marques, J. M., Yzerbyt, V. Y., \& Leyens, J. P. (1988). The "black sheep effect": Extremity of judgments towards ingroup members as a function of group identification. European Journal of Social Psychology, 18, 1-16.

McClelland, G. H., \& Judd, C. M. (1993). Statistical difficulties of detecting interactions and moderator effects. Psychological Bulletin, 114, 376-390.

Mendelson, M. J., \& Aboud, F. E. (1999). Measuring friendship quality in late adolescents and young adults: McGill Friendship Questionnaires. Canadian Journal of Behavioural Science, 31, 130-132. doi:10.1037/h0087080

Miller, W. E., \& the National Election Studies. (1994). American National Election Studies 
cumulative data file, 1952-1992 [Computer file]. Available at http://sda.berkeley.edu:7502/D3/NES92C/ Doc/n92c.htm

Mullen, B. (1983). Operationalizing the effect of the group on the individual: A self-attention perspective. Journal of Experimental Social Psychology, 19, 295-322.

Norton, M. I., Frost, J. H., \& Ariely, D. (2007). Less is more: The lure of ambiguity, or why familiarity breeds contempt. Journal of Personality and Social Psychology, 92, 97-105.

Robbins, J. M., \& Krueger, J. I. (2005). Social projection to ingroups and outgroups: A review and meta-analysis. Personality and Social Psychology Review, 9, 32-47. doi:10.1207/s15327957pspr0901_3

Rokeach, M., \& Mezei, L. (1966). Race and shared belief as factors in social choice. Science, $151,167-172$.

Rokeach, M., Smith, P., \& Evans, R. I. (1960). Two kinds of prejudice or one? In M. Rokeach (Ed.), The open and the closed mind (pp. 132-168). New York, NY: Basic Books

Rokeach, M., \& Rothman, G. (1965). The principle of belief congruence and the congruity principle as models of cognitive interaction. Psychological Review, 72, 128-142. doi:10.1037/h0021702

Rosenbaum, M. E. (1986). The repulsion hypothesis: On the nondevelopment of relationships. Journal of Personality and Social Psychology, 51, 1156-1166. doi:10.1037/00223514.51.6.1156

Sack, K., \& Elder, J. (2000, July 11). Poll finds optimistic outlook but enduring racial division. The New York Times, p. A23.

Selfhout, M., Denissen, J., Branje, S., \& Meeus, W. (2009). In the eye of the beholder: Perceived, actual, and peer-rated similarity in personality, communication, and friendship 
intensity during the acquaintanceship process. Journal of Personality and Social Psychology, 96, 1152-1165. doi:10.1037/a0014468

Shapiro, J. R., \& Neuberg, S. L. (2008). When do the stigmatized stigmatize? The ironic effects of being accountable to (perceived) majority group prejudice-expression norms. Journal of Personality and Social Psychology, 95, 877-898. doi:10.1037/a0011617

Sunnafrank, M. J., \& Miller, G. R. (1981). The role of initial conversations in determining attraction to similar and dissimilar strangers. Human Communication Research, 8, 16-25.

Tajfel, H., \& Turner, J. C. (1986). The social identity theory of intergroup relations (pp. 7 - 24). Chicago: Nelson-Hall.

Taylor, C. (2002). Black religious intellectuals: The fight for equality from Jim Crow to the twenty-first century. New York, NY: Psychology Press.

West, C. (1993). Race matters. Boston, MA: Beacon Press.

West, T.V., Magee, J.C., Gordon, S.H., \& Gullett, L. (2014). A little similarity goes a long way: The effects of peripheral but self-revealing similarities on improving and sustaining interracial relationships. Journal of Personality and Social Psychology, 107, 81-100.

West, T. V., Pearson, A. R., Dovidio, J. F., Shelton, J. N., \& Trail, T. E. (2009). Superordinate identity and intergroup roommate friendship development. Journal of Experimental Social Psychology, 45, 1266-1272.

Wetzel, C. G., \& Walton, M. D. (1985). Developing biased social judgments: The false consensus effect. Journal of Personality and Social Psychology, 49, 1352-1359. doi:10.1037/0022-3514.49.5.1352

Zick, A., Wolf, C., Küpper, B., Davidov, E., Schmidt, P., \& Heitmeyer, W. (2008). The syndrome of group-focused enmity: The interrelation of prejudices tested with multiple 
cross-sectional and panel data. Journal of Social Issues, 64, 363-383. 


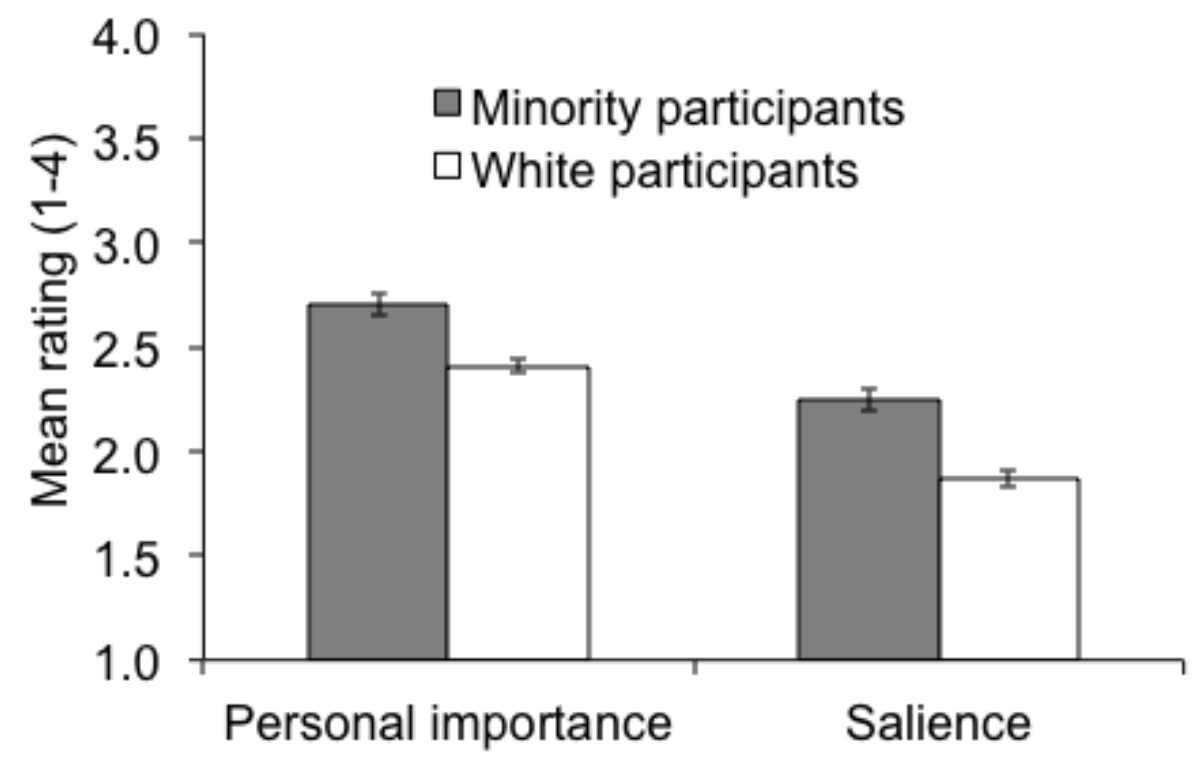

Figure 1. Personal importance and salience of race relations by participant race (Pilot Study). Error bars indicate $\pm 1 S E$ of mean. 


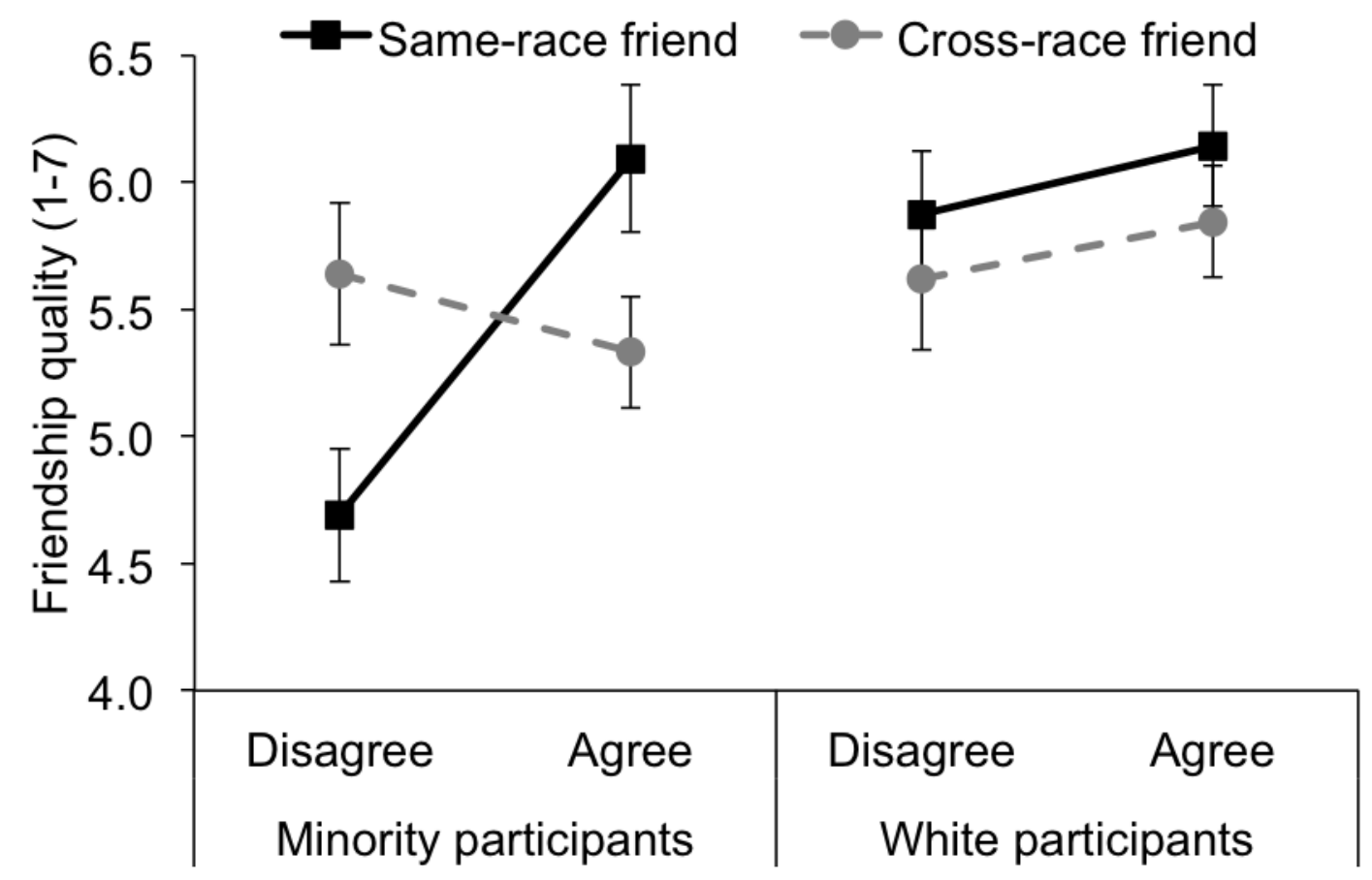

Figure 2. Friendship quality by participant race, dyad type, and racial attitude agreement (Study 1). Means are estimated for dyad members who are each $\pm 1 S D$ from the mean of racial attitudes, collapsing across (dis)agreement type. Error bars indicate $\pm 1 S E$ of mean. 


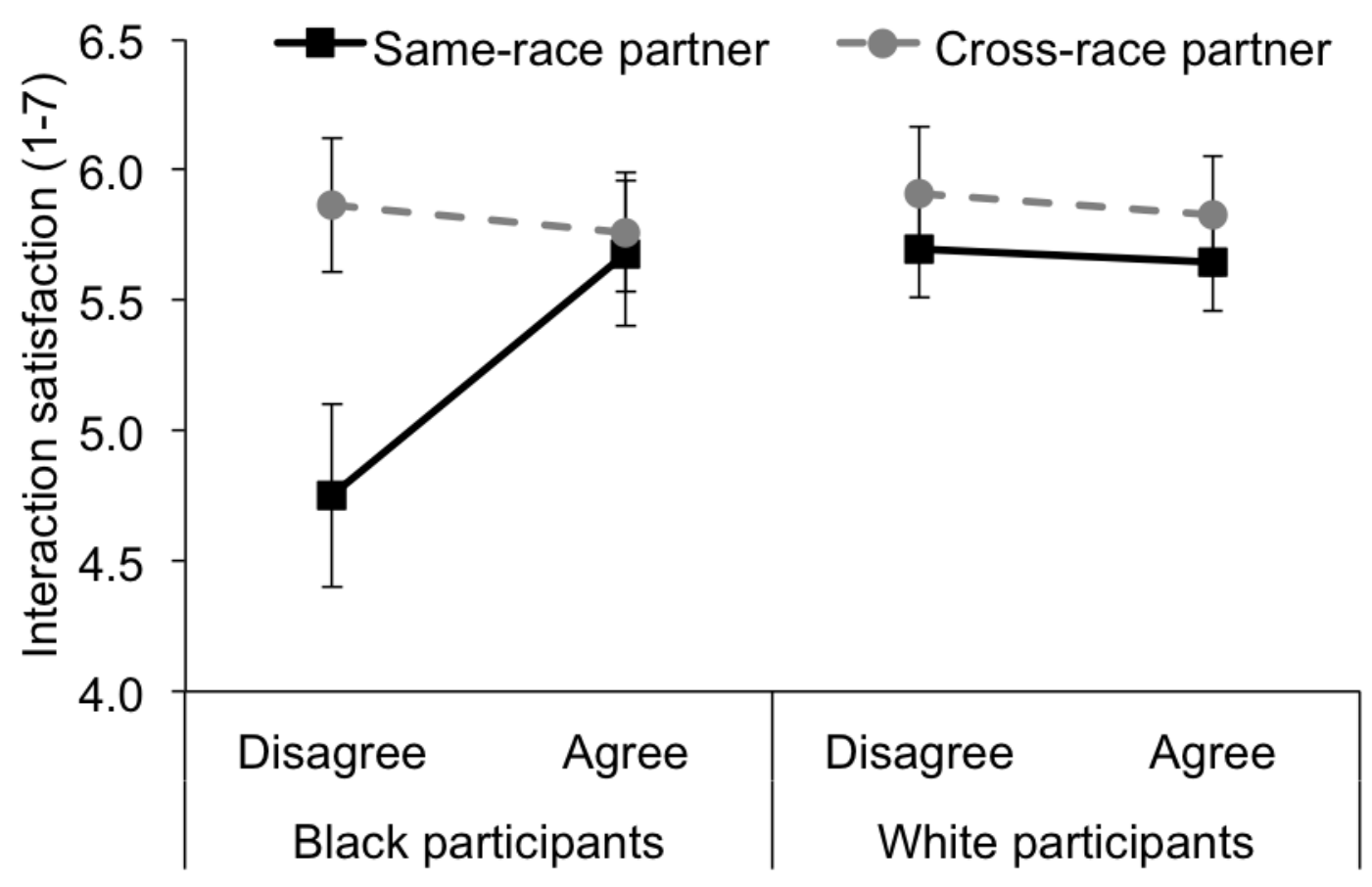

Figure 3. Interaction satisfaction by participant race, dyad type, and racial attitude agreement (Study 2). Means are estimated for dyad members who are each $\pm 1 S D$ from the mean of racial attitudes, collapsing across (dis)agreement type. Error bars indicate $\pm 1 S E$ of mean. 


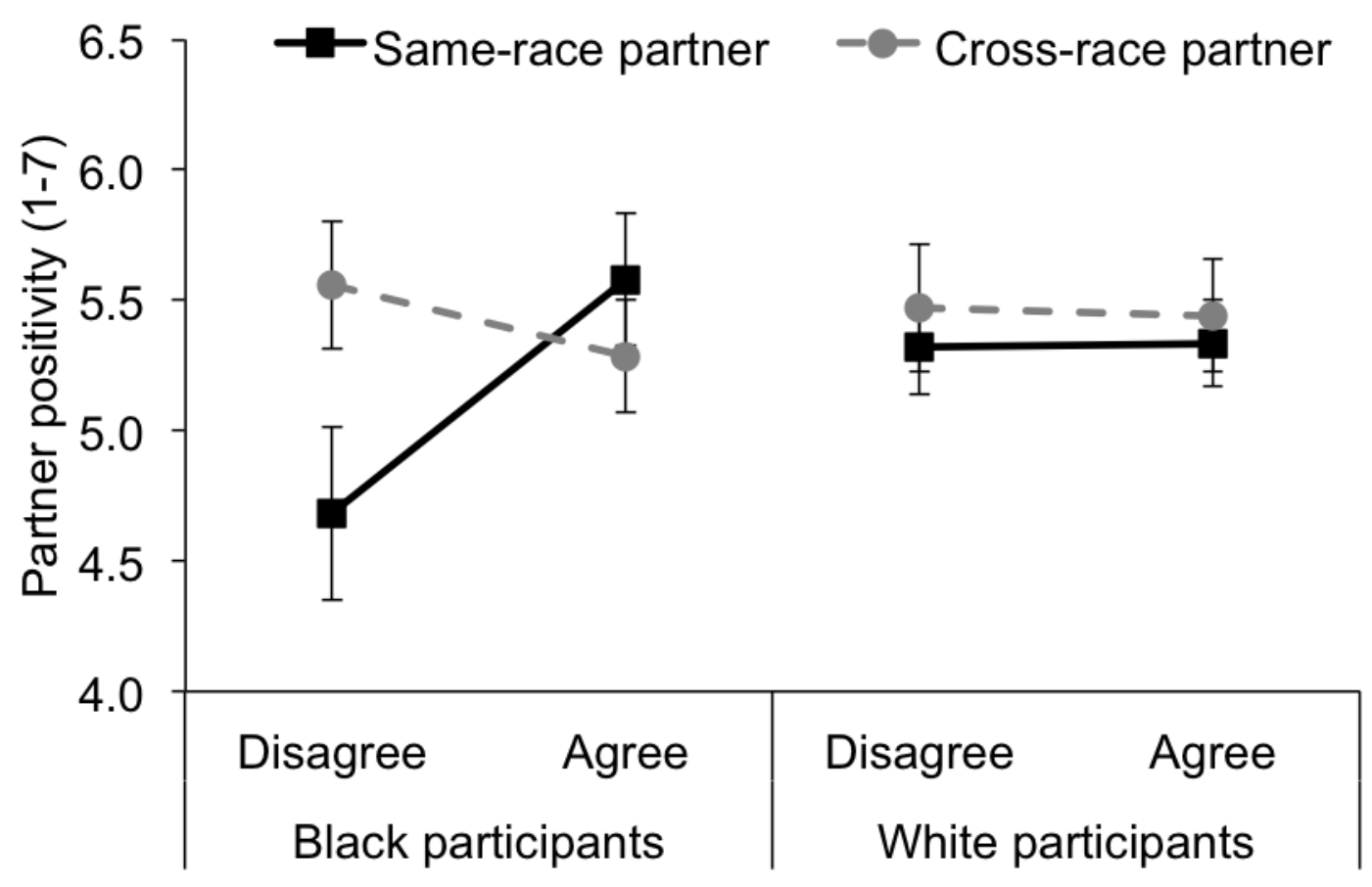

Figure 4. Partner positivity by participant race, dyad type, and racial attitude agreement (Study 2). Means are estimated for dyad members who are each $\pm 1 S D$ from the mean of racial attitudes, collapsing across (dis)agreement type. Error bars indicate $\pm 1 S E$ of mean. 


\section{Appendix A: Friendship Quality Items (Study 1)}

Imagine that the blank space in each item contains the person's name that you selected for this study. With him/her in mind, decide how much you agree with the item. Use the scale below.

$\begin{array}{lllllll}1 & 2 & 3 & 4 & 5 & 6 & 7 \\ \text { Strongly } & \text { Disagree } & \begin{array}{l}\text { Disagree } \\ \text { Somewhat }\end{array} & \text { Neutral } & \text { Agree } & \text { Agree } & \text { Strongly } \\ \text { Disagree } & & \text { Somewhat } & & \text { Sgree }\end{array}$

1. I am happy with my friendship with

2. I care about

3. I like a lot.

4. I am satisfied with my friendship with

5. I hope __ and I will stay friends.

6. I would miss ___ if he/she left.

7. __ helps me when I need it.

8. __ would make me feel comfortable in a new situation.

9. __ is someone I can tell private things to.

10. _ has good ideas about entertaining things to do

11. __ would want to stay my friend if we didn't see each other for a few months.

12. ___ makes me feel smart.

13. makes me laugh.

14. _ points out things that I am good at.

15. _ lends me things that I need.

16. w_ would make me feel better if I were worried.

17. compliments me when I do something well.

18. __ makes me feel special.

19. __ would stay my friend even if other people did not like me.

20. knows when something bothers me.

21. __ helps me when I'm trying hard to finish something.

22. ___ makes me feel that I can do things well.

23. __ would still want to stay my friend even if we argued.

24. __ is fun to sit and talk with.

25. ___ makes me feel better when I'm upset. 


\section{Appendix B: Racial Attitudes Items (Study 2)}

Parallel items from Attitudes Towards Blacks and Attitudes Towards Whites scales (ATB \& ATW; Brigham, 1993), with wording for ATW given in brackets and "R" denoting reversecoded items:

Instructions: Please use the scale below to indicate the extent to which you agree with each statement" from 1 (strongly disagree) to 7 (strongly agree).

1. I favor open housing laws that allow more racial integration of neighborhoods. ${ }^{\mathrm{R}}$

2. Racial integration (of schools, businesses, residences, etc.) has benefited both Whites and Blacks. $^{\mathrm{R}}$

3. Whites should support Blacks in their struggle against discrimination and segregation. ${ }^{\mathrm{R}}$

4. I think that Black [White] people look more similar to each other than White [Black] people do.

5. I would rather not have Blacks [Whites] in the same apartment building I live in.

6. If a Black [White] person were put in charge of me, I would not mind taking advice and direction from him or her. ${ }^{\mathrm{R}}$

7. It would not bother me if my new roommate was Black [White]. ${ }^{\mathrm{R}}$

8. Some Blacks [Whites] are so touchy about race that it is difficult to get along with them. 